\title{
DA PLURALIDADE DOS AFETOS Trajetórias e orientações amorosas nas conjugalidades contemporâneas
}

\author{
Sofia Aboim
}

É entre o eu e o tu que, aos olhos da consciência humana, se produz. a primeira das suas dissensões e a primeira das suas unificações. Georg Simmel, "Fragmento sobre o amor. Escritos póstumos”, Logos, 1921-1922

Os afetos não constituem um tema novo nas ciências sociais. Teorizado, entre outros, por Simmel (1998 [1895]) ou Goode (1959), o amor ganhou protagonismo crescente desde as primeiras décadas do século XX. Primeiro, tornou-se central na reconstituição histórica da vida privada, desde que Ariès (1973 [1960]) ou Shorter (1995 [1975]) elegeram a sentimentalização das relações familiares como uma das linhas de força da modernidade, frisando a importância do romantismo que, florescente no século XIX, concedeu destaque aos afetos - entre cônjuges, entre pais e filhos -, legitimando um ideal de famíliarefúgio, íntima e livremente escolhida (Costa, 2005).

Artigo recebido em junho/2007

Aprovado em fevereiro/2009
Do amor, princípio orientador das relações familiares, dependeriam a reciprocidade e a dádiva, organizadas contra a lógica de mercado imperante na esfera pública e contra os rígidos códigos de uma família, instituição voltada para a sobrevivência material do grupo, fortemente hierarquizada e subordinada ao poder inquestionável do patriarca. Mediante a força transformadora do amor, legitimaram-se novas conexões entre instituição e indivíduo, passando a predominar lógicas individualizadas que foram minando o holismo das sociedades tradicionais (Dumont, 1985). ${ }^{1}$ Neste ponto, Bourdieu (1998) vai ainda mais longe chamando ao amor "ilha encantada", o único momento em que é possível suspender a dominação masculina. $\mathrm{O}$ único momento em que os indivíduos são únicos e iguais, rompendo com as forças poderosas do englobamento e da subordinação.

O amor ganhou, portanto, enorme relevo na conceitualização da própria individualidade. $\mathrm{Na}$ 
atualidade, autores diversos como Elias (1993 [1939]), Beck e Beck-Gernsheim (1995), Giddens (1996) ou Luhmann (1991) têm focado o seu papel estruturante nos processos de individualização característicos da modernidade. O sentimento amoroso é, assim, um dos pilares da individualização. Primeiro, desafiou a instituição, constituindo uma força subversiva e ameaçadora da fundação matrimonial, subordinada aos interesses da reprodução familiar e social — no amor-cortês, ou mais tarde, no amor-paixão nascente na França do século XVIII, os afetos ficavam afinal à margem da aliança matrimonial (Solé, 1976; Gucht, 1994; Chaumier, 1999; Luhmann, 1991). O amor-paixão, que Stendhal (1999 [1822]) tão bem descreveu como oposto à razão, aos interesses exteriores, à integração do indivíduo na sociedade, e a instituição eram forças antagônicas, que o romantismo veio posteriormente reconciliar, trazendo o amor para dentro do casamento e elegendo-o como único critério legítimo na formação e na manutenção do casal.

Apesar de se assemelharem na reivindicação de liberdade amorosa e na valorização da singularidade do outro, o amor-paixão, ao contrário do romântico, caracteriza-se pelo erotismo forte, pelo encantamento fugaz, alheio a rotinas e deveres, pelo caráter invasivo e intensamente fusional, quase aprisionador. É por estas razões que a paixão aparece como tumultuosa e contrária à ordem social. Já o amor romântico, na interpretação de Giddens (1996), teve importante papel na organização da sociedade do século XIX. Apesar de cultivar a liberdade individual, o amor romântico perdeu as suas qualidades transgressoras e eróticas (Costa, 2005), para se adequar às lógicas sociais da diferenciação de gênero e da aliança familiar. Como propõe Chaves (2006, p. 835), este amor é um "amor romântico domesticado", diferente do original, inicialmente mais selvagem e erotizado.

No entanto, dominante durante a primeira modernidade ou modernidade organizada (Wagner, 2001), período marcado pela industrialização e urbanização emergentes no século XIX, o ideal de casal romântico, legitimado por um amor domesticado e sexualmente diferenciado, enfrentaria agora os desafios impostos pela crescente igualdade de gênero, a visão dinâmica e erotizada da relação e a valorização da individualidade (Giddens, 1996; Beck e Beck-Gernsheim, 2002). Na modernidade avançada, os ideais românticos seriam estreitos para conter a busca de auto-realização afetiva e a vida familiar individualizar-se-ia ainda mais, impondo novos desafios às lógicas holistas tradicionais (Dumont, 1985; Velho, (2002 [1986]); Vaitsman, 1994). Já não seria o duo conjugal a quebrar amarras com a comunidade e o parentesco, nuclearizando-se, mas o indivíduo a enfrentar as tensões entre a busca de liberdade individual e as gratificações amorosas de uma vida a dois.

Com efeito, o amor tem ganho popularidade na sociologia da conjugalidade e da família, constituindo, desde há muito, um tópico recorrente na análise das mudanças na vida privada (Singly, 1996; Edgar e Glezer, 1994; Velho, (2002 [1986]); Vaitsman, 1994; Salem, 1989; Dauster, 1984; Aboim, 2006; Torres, 2000). A passagem tendencial de modelos institucionalistas, arredados dos sentimentos, para a família moderna, teorizada desde Durkeim (1975 [1895]) a Parsons (1955), conta uma história feita de afetos. Antes de mais nada, a família é moderna porque afetiva. $\mathrm{O}$ casal parsoniano (Parsons e Bales, 1955) estereotípico encontrava-se unido pelo amor romântico entre duas naturezas distintas e complementares: a masculina e a feminina. Sentimentos e diferenciação de gênero eram perfeitamente solidários, promovendo a dependência e a fusionalidade e assim adaptando o casal às exigências do sistema social, industrializado e urbanizado. No entanto, desde cedo, se complexificou este ideal de conjugalidade. Burgess, Locke e Thomes (1960 [1945]), ao diagnosticarem o declínio da família-instituição, introduziram a noção de "companheirismo" para descrever um casal romântico e dependente, mas também negocial e tendencialmente paritário. Mais recentemente, Roussel (1991) sugeriu a idéia de "família-clube" como ex-libris do casal associativo moderno, ultrapassando-se, em larga medida, o companheirismo fusional que Burgess, Locke e Thomes haviam proposto. Similarmente, Théry (2000) faz referência à passagem do "casal cadeia", institucionalista e subordinado à reprodução social, ao "casal duo", afetivo, igualitário e autônomo. Singly (2000) diz que os indivíduos querem ser "livres em conjunto" (libres ensemble), 
utilizando o termo "dupla vida" para se referir ao paradoxo do individualismo contemporâneo: os indivíduos querem ter ao mesmo tempo uma vida conjugal, da qual depende sobremaneira a construção das identidades, e uma vida pessoal. No mesmo sentido, mas refletindo agora sobre o lado amoroso da vida a dois (Chaumier, 1999), sugere que a fusão afetiva, para ele associada ao amor romântico, seria paulatinamente substituída por uma espécie de "fissão" estruturada pela autonomia individual. Neste plano, Giddens (1996) propõe a noção de "amor confluente" (igualitário, negociado, centrado na satisfação mútua, não estritamente heterossexual), como modelo substituto de um amor romântico interpelado pela mudança.

Pesquisas em Portugal ou no Brasil têm igualmente desvendado os caminhos complexos da mudança e as desiguais distribuições dos valores "individualistas" em sociedades onde tradição e modernidade se justapõem permanentemente, permitindo, como afirma Domingues (2002, p. 67), uma maior plasticidade das identidades. No Brasil, destaca-se a extensa produção sobre as camadas médias urbanas, tidas como protagonistas das rupturas com os valores e as práticas tradicionais, holistas e hierarquizantes na linguagem dumontiana. A igualdade e o individualismo modernos teriam mais expressão entre estes grupos, favorecendo o florescimento de "novas formas de casal e de família", baseadas na autonomia e na auto-realização. Gilberto Velho (2002 [1986]) analisa a problemática do casamento e da aliança na sociedade carioca dos anos de 1980 observando como a busca de si mesmo e a psicologização do self tornaram-se discursivamente vitais, o que justifica, acima da continuidade do grupo, opções de vida individuais, rupturas e recomposições. Essas mudanças nos padrões de casamento e de família em segmentos de classe média urbana são, em grande medida, produto da transformação da situação das mulheres (Vaitsman, 1994) que, ao desafiarem o seu velho lugar no interior do espaço privado, permitiram novos quadros de flexibilidade e pluralidade. O exlibris desse movimento é retratado por Salem (1989) na sua pesquisa sobre o "casal grávido", uma forma extrema de casal igualitário, centrado em si mesmo e empenhado em tudo partilhar, como denota a intensa participação masculina na gestação, de acordo com três princípios éticos: psicologicidade, igualdade e mudança. Como afirma a autora, o "casal grávido" converte-se em recurso de aproximação para especular sobre uma ética fundada na configuração individualista-igualitária" (Idem, p. 1)

Em Portugal, os resultados têm apontado no mesmo sentido, vinculando os ideais de casal associativo, centrado na autonomia pessoal, às classes favorecidas, por contraponto às lógicas de aliança que perduram com mais vigor em meios populares (Aboim, 2006; Torres, 2000). No entanto, a colagem entre individualismo e classe social tem sido relativamente desconstruída, mostrando a pluralidade emergente nas sociedades contemporâneas. Num artigo publicado em 1997 sobre mulheres de baixa renda na periferia do Rio de Janeiro, Vaitsman deixa bem claros os limites das dicotomias igualdade/hierarquia ou tradicional/moderno, ao mostrar a adesão de mulheres de camadas populares a certas formas de individualismo. O projeto de vida, mais orientado para a luta pessoal travada para assegurar o bem-estar dos filhos do que para uma identidade institucionalista e centrada no casamento, assim o comprova. Durham (1997) havia já elaborado, a este propósito, uma crítica importante, alertando contra a linearização da associação entre igualitarismo/individualismo e classes médias e entre holismo/hierarquia e classes populares. A mesma linha de raciocínio aplica-se à realidade portuguesa, onde igualmente se descobrem sinais importantes de autonomia e busca afetiva entre indivíduos de meios menos qualificados acadêmica e profissionalmente (Aboim, 2006). Cada vez mais, se oscila entre a unicidade do laço afetivo e a proteção de parcelas da sua própria individualidade, engendrando processos de fragmentação da identidade.

Com efeito, a análise da conjugalidade estabelece estreita cumplicidade com o entendimento das formas de amor conjugal. Como diz Luhmann (1991), analisando de modo sistêmico os processos que tornaram a paixão e depois o romantismo códigos semânticos socialmente partilhados, o sentimento amoroso moderno, que é uma conseqüência da individualização social, deu ao conjugal imensa importância. Entretanto, o incremento da autonomia 
individual e do ideal de relação permanentemente amorosa tornam o casal romântico mais difícil de concretizar. O "amor confluente", de que nos fala Giddens (1996), trata disso mesmo, procurando diagnosticar as dinâmicas afetivas contemporâneas, relações entre parceiros iguais, que investem na transparência relacional e nas recompensas sexuais, enquanto tal empreendimento for satisfatório para cada um deles. Perenidade e fidelidade são questionáveis, desde que negociadas entre parceiros autônomos. A articulação entre aliança e sentimento, característica do romantismo, cede lugar à eclosão da paixão erótica entre iguais permitida pela individualização contemporânea. Em Sociedade e subjetividade (2002 [1986]), Gilberto Velho aborda a relação entre afetos e individualização, focando a importância da paixão, inesperada e fluida, tão elogiada entre as camadas médias da sociedade carioca dos anos de 1980, como símbolo do individualismo contemporâneo.

\section{Entre eu e nós: paradoxos das conjugalidades contemporâneas}

A importância do amor no fluir das relações sociais, na conquista de igualdade de gênero e na construção de si tem sido sobejamente sublinhada por vários autores e em diversos contextos. Ao amor é concedida, no entanto, uma qualidade dual: ele singulariza, apresentando-se simultaneamente como possibilidade redentora em face do lado negro da individualização. Essa capacidade unificadora é frisada por muitos autores. Para Luhmann (1991), a manutenção da identidade individual depende de instâncias particulares que a confirmem e a apóiem. Ora, numa sociedade altamente diferenciada, o amor transformou-se no único meio de comunicação entre a individualidade e um "mundo próximo". Também para Simmel (2004 [1921-1922]), o amor possuía essa capacidade de suportar a fragmentação do eu, ao mesmo tempo em que retirava o indivíduo de um todo indistinto, dando-lhe um caráter único. Do amor depende, como notam Singly (1996) ou Kaufmann (1999), a afirmação de uma identidade individual que, ante a pluralização e a impessoalidade dos círculos da vida pública, cada vez se refugiaria no âmago da vida privada. Similarmente, Kellerhals et al. (1982, p. 33) apontam que "é como 'oportunidade de sociabilidade', contra a fragmentação da pessoa, que se constitui o casal contemporâneo”. Por seu turno, Berger e Kellner (1975 [1962]) advogam que o casamento de amor serve como proteção contra a anomia, oferecendo ao indivíduo a coesão necessária para que ele possa dar sentido à sua existência. Todavia, a força individualizante do amor pode, por vezes, ser excessiva, gerando paradoxos e tensões, gerando as "tiranias da intimidade", para usar a expressão que Sennett (1986 [1974]) aplicou ao movimento de progressiva psicologização da vida pública.

Fala-se crescentemente, portanto, dos paradoxos das conjugalidades contemporâneas, divididas entre um ideal romântico de fusão afetiva permanente que, mesmo transformado, perdura, e o investimento na individualidade e na satisfação erotizada, mas transitória, da paixão amorosa. Féres-Carneiro (1998, p. 384) chama-lhe "o difícil convívio da individualidade com a conjugalidade". Para Simmel (2004 [1921-1922]), as tensões imanentes ao ideal contemporâneo de casamento decorrem da sua natureza hiperafetiva: o desejo pelo outro é de tal modo absoluto que é capaz de originar uma sensação de vazio, de esgotamento. A descontinuidade entre o plano dos afetos, objeto de tão elevadas expectativas, e o mundo das rotinas cotidianas podem gerar fragmentação e mesmo sofrimento (Velho, 2002 [1986]; Vaitsman, 1994). Além disso, a oscilação entre o desejo de fusão e a ênfase no eu constitui uma dinâmica complexa. Como nota Salem (1989), o “dois em um” do casal igualitário vai cedendo às demandas da individualidade, superada a fase de apaixonamento intenso. Nesse sentido, o aumento do divórcio e da recomposição conjugal retratariam precisamente a contestação da perenidade do casamento, mas mostrando, simultaneamente, a crescente importância do bem-estar individual e da paixão erótica na relação a dois. Não é afinal o enorme investimento num casamento de amor livre de constrangimentos institucionais que o expõe tão e cada vez mais freqüentemente à dissolução?

Se o amor romântico vinculava-se a um casal fusional e funcional (ao modo parsoniano), sexualmente diferenciado e estático na percepção da di- 
nâmica relacional (que as histórias românticas do "e foram felizes para sempre" tão bem tipificam), novos comportamentos na vida familiar refletem formas híbridas de combinar amor e conjugalidade, justapondo, de forma heterogênea, elementos de diversas semânticas do amor (Gucht, 1994; Neyrand, 2002; Douglas e Atwell, 1988; Velho, 2002 [1986]; Bozon e Heilborn, 1996). Resta saber como estas se entrecruzam na conjugalidade. Em que medida persistem os códigos do romantismo? Como se combinam com os ideários reavivados do amor-paixão, intenso, ausente de cotidiano, efêmero? E o amor autônomo, como tipificado na "relação pura" de Giddens, em que medida e com que especificidades existe entre os casais individualizados de hoje? Como resistem os afetos conjugais ao passar do tempo e de que modo se localizam em determinados grupos sociais?

Este conjunto de questões condensa os objetivos deste artigo. Num contexto de entrecruzamento entre romantismo e casal fusional, companheirismo e igualdade, paixão amorosa e autonomia individual, procuramos trazer à arena empírica o debate sobre a sentimentalização da conjugalidade e a crescente complexidade promovida pelos processos de individualização. De um lado, esperamos descobrir um cenário de pluralidade das semânticas afetivas $^{2}$ nas conjugalidades contemporâneas. Analisando discursos femininos, ${ }^{3}$ recolhidos em 22 entrevistas em profundidade realizadas com mulheres entre 30 e 40 anos, vivendo em conjugalidadade (casamento ou união consensual, primeiras conjugalidades e recasamentos) com filhos em idade escolar e residentes na área metropolitana de Lisboa (Portugal), ${ }^{4}$ tentamos identificar, de modo indutivo, diferentes orientações amorosas. Entretanto, cientes de que os afetos se (re)constroem ao longo do tempo, investigamos as orientações femininas no presente e no início da vida conjugal, analisando assim o efeito do trajeto sobre os discursos. De outro lado, procuramos articular afetos e dinâmicas conjugais, comparando mulheres pertencentes a diferentes camadas sociais. Por meio dessa dimensão afetiva retratamos formas plurais de individualização nas sociedades contemporâneas. A ênfase nos sutis cruzamentos entre as qualidades unificadoras e singularizantes do amor (ou dos amores para enfatizar a sua multiplicidade) ajudanos a decifrar os códigos relacionais atuais.

\section{Uma análise dos discursos femininos a dois tempos}

$\mathrm{Na}$ análise das orientações amorosas demos relevo à semântica utilizada para exprimir os sentimentos, focando a variedade terminológica dos discursos. Paixão, amor, amizade, desejo, companheirismo são afinal vocábulos empregues de várias maneiras e em conjugações diferentes. A contagem e a interpretação das palavras femininas teve como base um conjunto de perguntas que visavam a reconstituir o "trajeto amoroso" das entrevistadas, desde o namoro e o início da vida conjugal até o presente. Perguntamos-lhes o que sentiam pelo cônjuge no passado e quais as transformações ocorridas ao longo dos anos vividos em comum. Esta metodologia indutiva permite aferir a enorme diversidade de interpretações suscitadas pela dimensão afetiva. Como diz Dauster (1984, p. 525), “amores são vividos", propondo que é a partir de relações concretas que os indivíduos criam as noções de amor, tanto do amor cristão como do sexual. Com efeito, a autora, ao analisar os discursos sobre o amor, a amizade, a paixão, entre mulheres e homens de camadas médias do Rio de Janeiro, decompôs os significados plurais associados a estes termos, salientando a correlação entre a trajetória de vida e os significados do amor para o indivíduo.

Em concordância com esses postulados analíticos, identificamos várias orientações amorosas, mas também diferentes trajetórias sentimentais. Em vez de um discurso ou percurso hegemônico, são plurais as formas de representar, de viver e de reinventar ao longo do tempo o amor a dois. Descreveremos em seguida as orientações, os trajetos e também as tensões associadas a três grandes semânticas: o amor como paixão, como companheirismo ou como sentimento de "alternância". Observamos ainda, sempre partindo de exemplos empíricos, como cada uma delas se articula a diferentes concepções do casal mais ou menos centrado na fusão de individualidades ou na proteção da autonomia pessoal. 


\section{O amor como paixão: corpo e cotidiano}

Os termos "paixão" ou "estar apaixonado", traduzindo um dos ideários contemporâneos mais comuns, surgiram muito freqüentemente nas narrativas femininas, não obstante com sentidos diferentes. A pluralidade de significados, por vezes até paradoxais, da paixão reflete a sua relação complexa com a individualização da vida conjugal. De um lado, a paixão exige uma fusionalidade intensa do casal, de outro, pode fragilizar a aliança e promover a busca de si mesmo.

\section{Uma paixão corpórea}

Um dos significados emergentes alinha-se de perto com a semântica original do amor-paixão, revelando uma conexão difícil com o mundo das rotinas. O amor como paixão corpórea encontrase em discursos que, longe do romantismo e da aliança, elegem o laço existente na relação entre dois corpos, valorizando a paixão física intensa. Para Alice ou Rosa, duas entrevistadas de camadas intermédias, a semântica da paixão continua, passados alguns anos de vida em comum (quatro no caso da primeira, cinco no da segunda), a privilegiar a sexualidade, domínio eleito da proximidade conjugal. A percepção da mudança afetiva não é, assim, ressaltada, acabando as mulheres por narrar, em tons místicos, as suas histórias conjugais, vinculando-as à idéia de encontro sexual extraordinário.

\section{Sentimento inicial}

"Paixão, pode-se dizer. Estava apaixonada. E depois claro a paixão física. Sempre".

Transformações ao longo do tempo

"Sinto um laço forte... Paixão. Sou mesmo casada com ele [...], embora mantenha a minha individualidade, os meus pequenos quartos secretos... enfim, não me entrego assim toda, todinha. Sou mulher daquele homem [...], embora depois haja uma data de coisas a afastar-nos... O assunto da cama é que é sempre bastante animado".

Rosa, 39 anos, publicitária, $11^{\circ}$ ano, $3^{\mathrm{a}}$ união consensual; duração: 4 anos
Trata-se de um amor algo falho de cotidiano, próximo do ideal-tipo de "amor-paixão". Mas, contemos um pouco das histórias conjugais destas mulheres, recasadas e impelidas pelas circunstâncias a buscar uma independência pessoal que constitui hoje um elemento essencial das suas identidades.

Alice e Rosa têm em comum a escolaridade secundária, embora com profissões relativamente bem remuneradas: a primeira trabalha num barco sueco e a segunda no setor da publicidade. Ambas vivem em união consensual, respectivamente pela segunda e terceira vez, e têm vários filhos (de anteriores relações e também da atual). Ambas passaram por várias rupturas e recomposições, continuando a experimentar instabilidade afetiva, em cenários conjugais atribulados e de grande separação cotidiana. Com seus parceiros pouco partilham tarefas, responsabilidades, despesas, lazeres. O companheiro de Alice (ex-presidiário e ex-toxicômano) está desempregado, vivendo ocupado pelas sociabilidades com seu grupo de amigos; o de Rosa também não tem emprego fixo e passa o tempo em encontros de motards, saindo de casa sem dia para voltar. São elas a fonte de sustento do lar e dos filhos, bem como a figura educadora, em casa. Entre o casal, carecido de cotidiano, restam os encontros sexuais marcados pela paixão.

Se pensarmos no amor-paixão como sentimento quase místico e fortemente sexualizado, que existe contra e fora do cotidiano, encontramos encaixe para o discurso destas mulheres. Alice e Rosa exprimem a continuidade inalterada dos encontros apaixonados, dizendo "há uma essência comum" e "sou mulher daquele homem". Embora haja problemas, e, como diz Rosa, "uma data de coisas a afastarnos", o sentimento conjugal vai permanecendo com a mesma incerteza apaixonada do começo da relação, com maior peso da sexualidade do que da aliança. Como notou Féres-Carneiro (1998), comparando dez casais em primeira conjugalidade e dez recasados das camadas médias cariocas, a exaltação da sexualidade é muito mais comum em situações de recasamento, como as que aqui descrevemos. A relação conjugal acaba por ser também vivida de forma mais individualizada e sensível à instabilidade da paixão. Gilberto Velho encontrou discursos sobre os imperativos da paixão entre camadas médias 
individualizadas do Rio de Janeiro dos anos de 1980. No entanto, a semântica da paixão e a individualização dos projetos de vida podem ser encontradas mesmo em grupos sociais menos qualificados, como aqui acontece. As trajetórias afetivas instáveis parecem levar à erosão do investimento romântico numa relação cotidiana e durável. Ao mesmo tempo em que as mulheres deixam de ver no homem a figura de apoio e sustento da família, guardam (Vaitsman, 1997), ainda assim, elementos de paixão, os únicos que sobrevivem à falta de rotinas.

\section{A paixão cotidianizada}

Uma segunda orientação amorosa partilha com a primeira um discurso presente vinculado aos termos "paixão" ou "chama sempre acesa", em continuidade com o sentimento inicial. Contudo, ao contrário do anterior, a semântica da paixão serviu para alimentar a proximidade cotidiana no casal. Trata-se assim de um "amor apaixonado" fusional e rotinizado, mais próximo de um romantismo original, não domesticado, que valoriza a sexualidade e, mais do que tudo, a relação a dois.

Preferimos utilizar a expressão "amor-apaixonado", procurando torná-la alternativa aos ideaistipos de "amor-paixão" (não cotidiano, fortemente sexualizado, possessivo, arrebatador) ou de "amorromântico domesticado" (fundado sobre a expressividade feminina, a diferenciação de gênero, a proximidade intuitiva). O amor apaixonado pretende, enfim, designar começos amorosos sexualizados, mas permanentemente reconstruídos. Afinal, concluímos, "estar apaixonada" é expressão de significados múltiplos, associada a formas diferenciadas de conjugalidade.

A percepção de se estar apaixonada depois de anos vividos em comum alia-se a um "nós conjugal" alimentado pelas rotinas, as responsabilidades domésticas e os filhos. O "apaixonamento" é visto como processo dinâmico, amadurecendo pela extensão da partilha fusional no casal. O estar juntos, os ritmos comuns (como o ir dormir ao mesmo tempo), o diálogo e a intimidade ancoram um discurso dominado pelos lados emocionais da vida em comum. A cooperação instrumental cotidiana, também valorizada (ainda que a igualdade nas prá- ticas seja por vezes relativa), aparece como suporte do sentimento: o apoio mútuo é uma condição essencial para alimentar a proximidade e a "paixão" entre o casal.

\section{Sentimento inicial}

"Ah, sei lá. Eu acho que era uma doença. O homem saía à noite, eu parece que já estava cheia de saudades mal ele saía ao fim de cinco minutos".

\section{Transformações ao longo do tempo}

"Em termos de paixão [...]. Pronto, eu digo que o meu dia a dia sem o meu marido não era nada. É o meu braço direito, sem dúvida. É uma chama sempre acesa. É assim, a confiança aumentou imenso, muito mesmo. A total confiança não se adquire num ano de namoro. É com o passar dos anos. E para mim, aquela chama está sempre acesa".

Raquel, 36 anos, proprietária de loja de roupas, $6^{\circ}$ ano, $1^{\circ}$ casamento religioso; duração: 17 anos

Esta visão aparece nos relatos de mulheres com diferentes capitais escolares e profissionais (Raquel tem apenas o $6^{\circ}$ ano do ensino básico, mas é dona do seu próprio negócio, Rita é licenciada e assessora de edição de uma revista científica), mas que, por valorizarem imensamente a dinâmica interna do casal, não investem fortemente em projetos profissionais autônomos. É interessante que este discurso apaixonado seja comum a mulheres de diferentes camadas sociais. Embora o ímpeto fusional seja mais forte quando a escolaridade feminina é mais baixa, o ideário amoroso é relativamente partilhado. Tanto Raquel como Rita casaram cedo (respectivamente com 19 e 23 anos) e habituaram-se, desde logo, a centrar suas individualidades na vida de casal, distanciando-se mesmo, por razões de conflito, das famílias de origem. O casal e a família nuclear passaram, assim, a ser a sua grande ancoragem emocional, porto de abrigo fusional para o eu.

Compreende-se, portanto, a transversalidade social de um ideário amoroso que articula o lado apaixonado à proximidade fusional entre o casal, destacando a partilha íntima, comunicacional e 
sexual, em detrimento de dimensões de aliança e de integração do casal no grupo de parentesco ou na comunidade. Interligam-se referências historicamente construídas sobre o amor. A harmonia e a serenidade do amor romântico domesticado misturamse com a sexualização da semântica da paixão, num quadro repleto de características modernistas. Tal como entre casais igualitários descritos por Salem (1989), aqui a fusão intensa do apaixonamento aliase à busca de igualdade entre cônjuges e ao centramento no duo conjugal.

\section{A efemeridade da paixão: duas trajetórias}

$\mathrm{Na}$ reconstrução discursiva feita pelas mulheres, a maioria das conjugalidades inicia-se pelas portas da paixão. Contudo, em muitos casos, a vida em comum, o nascimento dos filhos e até as mudanças a nível pessoal são fatores enumerados para justificar uma transformação emocional que, freqüentemente, era esperada e considerada "natural". Várias mulheres se referem àquilo que para elas é um saber óbvio: os sentimentos mudam com o tempo e com a convivência a dois. Assim, uma das principais dinâmicas dos discursos femininos identifica a passagem de um amor-apaixonado para um amor-amizade.

Se as palavras retrospectivamente utilizadas para qualificar o sentimento inicial pelo cônjuge destacam os termos "paixão", "amor", "estar apaixonada", atualmente as referências relevam o amor-amizade e o companheirismo, dando conta do "arrefecimento" e da transformação da paixão inicial. Luhmann (1991) identifica nesta evolução uma salvaguarda da perenidade do próprio casamento, contra a fragilidade do "amor-paixão", rápido e freqüentemente dissolúvel. $\mathrm{Na}$ busca de fundamentos sólidos para uma relação duradoura, uma solução seria precisamente a proposta pela noção de "companheirismo". Afirma o autor (Idem, p. 203) que "no matrimônio não se procura um mundo ideal, elevado à qualidade de irreal e muito menos uma efetivação permanente dos sentimentos passionais, mas uma base para compreender e realizar em conjunto tudo aquilo que é importante para a pessoa". Neste caso, tal máxima parece aplicável. No entanto, como veremos, a essa dinâmica nem sempre subjazem as mesmas motivações.
Os casos descritos a seguir perfilam a passagem de um discurso sobre o apaixonamento para uma semântica do amor-amizade, traduzindo o que Salem (1989, p. 10) denominou "impreterível 'necessidade de discriminação"'. Esta mudança-chave pode ser, entretanto, percebida em função de diferentes processos subjetivos. Nuns casos, o nascimento dos filhos parece ser o fator-chave da mudança sentimental (percepção centrada no evoluir da dinâmica familiar), noutros, associam-se as transformações ao amadurecimento pessoal (percepção autocentrada). Vejamos um exemplo da primeira dinâmica, associada a formas de individualização mais comuns nas camadas populares (Vaitsman, 1997).

Para Telma, as transformações afetivas vinculam-se ao nascimento das duas filhas (hoje com 10 e 16 anos). A partir daí o duo cresceu, impondo a repartição do afeto antes exclusivamente canalizado para o casal. Com a passagem de casal para família, perde-se em amor-apaixonado, associado a uma fase de dedicação exclusiva ao cônjuge, e fabrica-se a amizade.

\section{Sentimento inicial}

"Muito amor, não é? Estava apaixonada por ele".

Transformacões ao longo do tempo

"Pronto, não posso dizer que é aquela paixão, aquele fogo como era há 20 anos atrás. É diferente. Não sei o que é que acontece com as outras mulheres mas comigo é assim. Há uma amizade grande depois de tantos anos, e temos os nossos filhos, a nossa vida... acho que com o nascimento dos filhos as coisas mudam".

Telma, 37 anos, empregada doméstica, $6^{\circ}$ ano, $1^{\circ}$ casamento (coabitação e religioso); duração: 19 anos

O amor-amizade constrói uma aliança (Roussel, 1991) permeada de algum romantismo, mas em que as componentes instrumentais e de gênero são importantes. O projeto familiar, orientado para o futuro dos filhos, existe num quadro de divisão de tarefas e de competências: ao marido (operário industrial) compete, mais do que à mulher, a responsabilidade de prover, e a esta cabem, em contrapartida, responsabilidades acrescidas nas tarefas da 
casa e na educação dos filhos. A solidez da "grande amizade" fabrica um laço de complementaridade, cujo centro são, acima de tudo, os filhos.

Todavia, a percepção do evoluir do sentimento pode vincular-se a uma outra ordem de razões, agora colocando o ônus no amadurecimento pessoal, processo autocentrado e sem conotação com acontecimentos exteriores. Entre as camadas médias, os discursos tendem a quedar-se por forte psicologização, como foi notado, no caso brasileiro, por diversos autores (Velho, 2002 [1986]); Vaitsman, 1994; Salem, 1989). É pelo menos esta a lógica enunciada por Alexandra, mulher com escolaridade elevada, em fase de investimento profissional e pessoal:

\section{Sentimento inicial}

"Acho que casei muito apaixonada".

Transformações ao longo do tempo

"Hoje é mais uma grande amizade. Acho que é uma coisa diferente. Muito mais forte. Chorase muito menos. De início é tudo um grande drama, chora-se muito e agora não. O companheirismo é fundamental. [...] Houve mudanças. Houve, nós também mudamos, já não somos as mesmas pessoas. Amadurecemos, acho!" Alexandra, 37 anos, dona de boutique e estudante, licenciatura incompleta, $1^{\circ}$ casamento religioso; duração: 12 anos

No companheirismo do presente conjugal reflete-se o investimento em si, uma progressiva dose de autonomia pessoal. A quebra da paixão fusional permite individualização pessoal, dando agora espaço ao desafio de construir "uma unidade com dois" (Salem, 1989, p. 10). Quando casou, Alexandra tinha concluído um bacharelato em administração e marketing e começou a trabalhar com o marido num negócio de revenda de roupa. Quando nasceram os filhos (dois gêmeos atualmente com 5 anos), Alexandra deixou de trabalhar para prestar assistência aos bebês; passado três anos resolveu montar um negócio só seu e, simultaneamente, voltar a estudar. Na dinâmica familiar, este processo de reinvestimento profissional e acadêmico refletiu a transição de uma fase orientada pela fusão conjugal (que dominava também na esfera sentimental, mais apaixonada e "dramática" do que hoje) para uma de maior autonomia. Como ela própria refere "[...] antes andávamos muito mais atrelados um ao outro e isso não era muito positivo".

Marido e mulher tiveram de se tornar mais companheiros, mais cooperantes, para que ela tivesse a possibilidade de voltar a estudar no período noturno, conciliando esta nova atividade com as responsabilidades da vida familiar. Provavelmente, a dinâmica de desenvolvimento pessoal aqui salientada não é alheia à valorização de um sentimento de companheirismo conjugal, fabricado após o período de começo apaixonado, lógica e necessariamente mais fusional. Com o tempo, a descoberta progressiva da autonomia acompanhou as transformações afetivas, passando-se da indiferenciação apaixonada à individualização simétrica entre o casal.

Esta passagem, nem sempre fácil, está claramente documentada no trabalho de Salem (1989). Mas outros autores enunciaram processos similares, assinalando os perigos das "tiranias da intimidade", e da fusão entre ego e alter (Simmel, 2004 [1921-1922]), para a autonomia pessoal (Sennett, 1986 [1974]). Nos processos descritos, fica expressa a natureza dual da paixão: a singularidade da individualidade é obtida pela alteridade liberta de constrangimentos que a paixão simboliza, mas a permanência do estado de paixão acaba por constituir entrave a projetos pessoais e investimentos na vida pública, podendo transformar-se em fonte de conflito e tensão na relação conjugal. Esses perigos foram assinalados pelo próprio Freud (1971 [1929]), ao ressaltar que a paixão dilui as fronteiras entre ego e objeto, dando a impressão de se ser um só. Ora, para o autor, a vida psíquica deverá aliar a capacidade de fusão e a de diferenciação. Sem este último processo, perder-se-ia a noção de si mesmo.

Embora no anterior exemplo tenhamos documentado processos de rotinização do apaixonamento em conformidade com ideais românticos não domesticados, assim evidenciando a independência do nós-casal em face de lógicas institucionalistas tradicionais, a maioria das trajetórias afetivas femininas vem encaixar-se na dinâmica agora descrita. Tanto em camadas populares como nas médias, assistimos a formas de diferenciação do eu que compõem um retrato matizado dos processos de individualização nas sociedades contemporâneas. 


\section{Amor romântico, aliança e companheirismo}

Em contraste com a semântica da paixão, os discursos sobre o amor, o companheirismo, a amizade encerram visões românticas do casal que, embora diversas, são geralmente promotoras de lógicas pouco individualistas, cimentando ideais de complementaridade, aliança e projeto familiar forte mesmo entre mulheres de camadas médias urbanas. O trajeto amoroso, menos subordinado aos códigos da paixão, sofre também menos o efeito do tempo, na forma como é relembrado.

\section{Um amor romântico domesticado}

Uma dessas orientações exalta a natureza indefinida amor e, ao contrário da maioria, as alterações construídas pelo tempo não são assinaladas. $\mathrm{O}$ caráter subjetivamente estático dos sentimentos pelo cônjuge corporifica-se num forte romantismo, descrito de forma quase mística (o marido é a alma gêmea). Quem o diz são mulheres católicas praticantes, com poucas qualificações acadêmicas, casadas na Igreja pela primeira e única vez. Mulheres para quem a perenidade do casamento é um valor sacramental, a diferenciação de gênero algo naturalizado e a dimensão erótico-sexual secundária quando comparada com a natureza espiritualizada da relação.

\section{Sentimento inicial}

"Somos parecidos em tudo. Portanto, quando eu o conheci, acho que pareceu-me que encontrei a minha alma gêmea... Há qualquer coisa, não estou a falar de paixão, nem de amor... é algo mais que nos une e não sei explicar o que é, mas sei que existe qualquer coisa. Temos uma grande ligação em tudo, exatamente".

Transformações ao longo do tempo

"Não, para mim penso que não houve mudanças... entre marido e mulher há uma grande cumplicidade. É que tudo o que se passa, contolhe...e ele também. Que seja bom, que seja mau... há um grande diálogo entre nós e para mim, faz de conta que ele é... não tenho um filho, penso que tenho dois!"

Matilde, 38 anos, vendedora de publicidade, $11^{\circ}$ ano, $1^{\circ}$ casamento religioso: 21 anos
Alguns traços característicos do ideal de amor romântico encontram-se presentes: a idealização mística da união e do parceiro, a ausência de percepção de mudanças, a visão da relação centrada numa proximidade apriorística (a cumplicidade advém de uma semelhança de alma), o relevo dado à complementaridade de gênero. Mas trata-se de um romantismo claramente domesticado por papéis de gênero diferenciados. A imagem de mulher-mãe, pouco sexualizada e portadora de capacidades expressivas relevantes é salientada, opondo-se-lhe a imagem masculina de proteção, segurança, sustento. Matilde coloca esta questão de modo explícito ao referir-se ao marido como sendo um segundo filho de quem tem de cuidar.

A história de Matilde é ilustrativa. Começou a namorar com o marido muito nova (com 12 ou 13 anos), tendo vindo a casar-se com 17 anos, de modo a anular a distância geográfica que os separava: Matilde era filha de emigrantes na França e ele vivia em Portugal. Apoiada no que achava ser o seu destino, e na liberdade que o amor legitima, contrariou os pais, deixou de estudar e casou-se apressadamente com o marido, operário de profissão. A partir daí começaram, como Matilde salienta, a viver um para o outro quase que exclusivamente, ocupando-se ela das tarefas do lar, só nascendo o único filho do casal passados dez anos de tentativas fracassadas. Crescimento conjunto é a expressão que ela própria utiliza, referindo-se sempre que ambos são tão parecidos que nem precisam de falar para se compreenderem. Uma união precoce associada a uma visão romântica do casamento, que Matilde apóia grandemente na sua forte religiosidade católica, favoreceu uma integração conjugal de ma-triz fusional, em que até hoje não houve espaço para mudanças. Para Matilde, tudo permanece igual aos primeiros tempos, não tendo havido sequer grandes alterações após o nascimento do seu primeiro e único filho: se algumas rotinas foram alteradas no que respeita a saídas e lazeres, o relacionamento entre o casal permaneceu, no essencial, o mesmo. Neste caso, a orientação romântica, domesticada, apóia-se na diferenciação de gênero e em dimensões de aliança, afastando-se de valores de igualdade, realização pessoal e reflexividade relacional. 
O companheirismo como ética de vida a dois

Os relatos mais comuns entre as entrevistadas estão, todavia, distantes deste romantismo estático. Privilegiam uma ética de companheirismo que, em vez de se construir como sentimento dominante no rescaldo de uma fase de "apaixonamento", esteve presente desde o início. Nestes casos, normalmente associados a mulheres de camadas médias, escolarizadas e profissionalmente empenhadas, a semântica do amor começa desde logo a construir-se em torno do sentimento de amizade.

\section{Sentimento inicial}

"[...] éramos muitos amigos, aliás o meu marido sempre gostou muito de mim desde o início do liceu, e eu de certa forma estava mais preocupada com outras coisas e sempre andei mais fugida e pronto na altura havia uma grande amizade e...".

\section{Transformaçoes ao longo do tempo}

"Existe uma grande amizade, existe um grande carinho, um grande companheirismo, uma grande partilha, pronto, digamos que a amizade cresceu muito entre nós os dois".

CARlota, 33 anos, professora e dona colégio, licenciatura, $1^{\circ}$ casamento religioso; duração: 10 anos

Este companheirismo conjugal liga-se a duas idéias. Uma elege a cooperação instrumental (nas tarefas, nas decisões) e expressiva (no diálogo constante, no apoio emocional) como componente básica do casamento. A outra destaca a importância do projeto familiar comum. Lutar a dois para realizar determinados objetivos (ter uma casa, ter uma família, progredir economicamente, educar os filhos de determinada forma etc.) é uma das grandes metas do casamento, sempre uma relação de aliança familiar. O próprio funcionamento do cotidiano conjugal depende, em última instância, da proximidade em matéria de ideais e visões de mundo: pode tratar-se da partilha de idéias relativas à educação dos filhos, ao bem-estar econômico, a opções sociais e políticas ou religiosas. Cooperação, projeto e amizade são, assim, três palavras-chave de uma semântica do companheirismo que privilegia como sentimento o amor-amizade, como dinâmica a cooperação e como fundamento um projeto de vida comum. Projeto de vida que é obviamente um projeto de família, desenvolvido num quadro de relações de parentesco mais alargadas.

No presente, encontramos sentimentos de companheirismo consolidados pela ação de partilhar a vida de modo fusional, em quadros de relativa igualdade. Procura-se não a complementaridade, mas a cooperação entre cônjuges. O próprio liame sentimental depende dessa cooperação. Foi por meio dela, e não tanto de arroubos emocionais, que se produziu a afinização progressiva entre parceiros, unidos pelo projeto comum de construir uma família. Para Carlota, professora do ensino básico no colégio de que sua família de origem é proprietária, casar e ter filhos é simultaneamente uma função social a desempenhar e um "destino espiritual” a cumprir. Todavia, este projeto familialista não é incompatível com certos valores modernistas. Afinal, uma relativa igualdade de gênero subjaz à cooperação conjugal. Alguma autonomia pessoal é também valorizada, quebrando o registro fusional, e até institucionalista, com que se descreve a conjugalidade e a família. Entre mulheres de camadas médias, as dimensões de aliança, aliadas de um romantismo suave e domesticado, podem assim ter importância, embora transformadas por outros valores. Esses processos mostram, entretanto, a não linearidade entre classe social e individualização, evidenciado a complexidade dos ideais de autonomia nas sociedades contemporâneas.

\section{Uma "lógica de alternância"}

Nestes últimos discursos existe, como em outros, a valorização de um amor apaixonado. Contudo, há diferenças importantes. Uma delas reside na relação entre amor e rotinas. Enquanto o "companheirismo apaixonado", retratado anteriormente, se alimenta do próprio cotidiano, aqui as rotinas constituem uma "ameaça" (pelo menos um entrave) à vivência plena de um sentimento apaixonado. Este contrasta com a rotina: é difícil ter uma vida profissional, realizar-se como pessoa, ser mãe e educadora, cuidar dos assuntos domésticos e financeiros e, 
ao mesmo tempo, manter-se permanentemente apaixonada pelo cônjuge. O companheirismo é assim um sentimento vital para sustentar a cooperação necessária e desejável, enquanto a paixão se reencontra em certos momentos que continuam a ser perseguidos na vida conjugal.

Entre companheirismo e momentos de paixão, essas trajetórias caracterizam-se por uma lógica de alternância, apresentando-se plenas de desafios: valorizam-se a individualidade e a realização pessoal, mas também a família e a maternidade; dá-se relevo ao "nós-casal" apaixonado e sexualizado, mas também à amizade e ao companheirismo. A variedade de termos utilizados para descrever o sentimento inicial (paixão, amizade, amor, desejo) enuncia, desde logo, a existência de uma semântica amorosa multifacetada, que assinala, aliás, mais um ponto de diferenciação diante de situações anteriormente descritas.

No leque de casos pesquisados, esta orientação afetiva é a mais próxima do ideal-tipo proposto por Giddens (1996). Para o autor, a relação pura do amor confluente distingue-se do amor romântico em vários aspectos: uma visão simétrica do gênero, a noção dinâmica de que o que conta é a relação especial e não a pessoa especial, a valorização da autonomia individual, a noção de contingência e de necessidade permanente de construção, a visão da intimidade sexual como algo que precisa de ser alimentado. Seria precisamente este tipo de relação aquele que melhor representaria o "paradoxo da conjugalidade contemporânea” (Neyrand, 2002), ou seja, a divisão entre a fusão amorosa imanente ao desejo de intimidade, comunicação intensa e paixão sexual e a autonomia individual valorizada e perseguida pelos parceiros.

O termo "paradoxo" parece, no entanto, excessivo para falar dos dilemas enfrentados pelas conjugalidades contemporâneas, modernistas e associativas, divididas entre o "eu" e o "nós". Todos os estilos de conjugalidade comportam tensões e dificuldades específicas (Widmer et al., 2003), desde as mais institucionalistas até as mais românticas e fusionais. O que importa acima de tudo é o lugar simbolicamente concedido ao conflito no espaço da relação. Quanto maior o grau de exigência, autonomia e reflexividade, maior a ênfase na negocia- ção conjugal, nas vontades e nas decisões de cada um, na articulação entre tempos e espaços individuais e coletivos, no próprio evoluir do lado amoroso da conjugalidade. Optamos, assim, por utilizar o termo alternância para designar esta orientação em que discursivamente se mistura a semântica do amor-amizade com a do amor-paixão.

O principal "paradoxo" sentido pelas mulheres é imposto pela presença de rotinas cotidianas que dificultam a manutenção de uma paixão para a qual escasseia o tempo. Entretanto, os sentimentos apaixonados são fundamentais para distinguir uma relação conjugal de uma de amizade: tanto para Adriana como para Carolina é importante um casal ser mais do que uma união promovida pela amizade. Fundar a relação sobre tais pressupostos, exigentes de cooperação cotidiana, de diálogo, partilha e simetria, mas também de momentos de paixão e espaço individual, é uma empreitada dinâmica, exigente de uma permanente construção.

\section{Sentimento inicial}

"Estava apaixonada. Era um sentimento de paixão, de amor, de amizade...".

Transformaçoes ao longo do tempo

"É um clássico dizer que a paixão não dura sempre! Quando as pessoas já vivem juntas há muito tempo, e nós apesar de tudo já vivemos juntos há muito tempo, obviamente não estamos tão apaixonados como estávamos aos 18 anos, aos $20 \ldots$ porque conhecemo-nos muito bem, enfim, já refreamos os ímpetos iniciais da paixão e sobretudo a vida rotineira e mais ou menos stressante que vamos levando também se encarrega de pôr um certo travão nesse sentimento de paixão... Apesar de tudo, acho que continuamos bastante apaixonados um pelo outro e que... não com as mesmas características da paixão inicial... Mas acho que continuamos com uma boa dose de paixão. [...] Ainda não entramos na fase do "já somos só grandes amigos". Claro que somos grandes amigos, mas acho que continuamos a ser bastante mais do que isso".

AdrIANA, 37 anos, professora universitária, doutoramento, $1^{\mathrm{a}}$ conjugalidade (coabitação e casamento civil); duração: 13 anos 
Outra característica importante reporta-se ao investimento profissional feminino. Ainda que os encargos domésticos e com os filhos pesem na vida das mulheres, a cooperação dos cônjuges, a presença de uma empregada doméstica e uma boa base de apoio familiar (nomeadamente nos cuidados às crianças) concorrem para facilitar um investimento profissional forte, condição essencial de uma valorizada autonomia. Autonomia e realização profissional são, aliás, elementos dos quais depende a própria satisfação conjugal. A preservação da autonomia não se apresenta contra o sentimento amoroso e a proximidade conjugal, mas como condição necessária para uma conjugalidade feliz. E, uma conjugalidade feliz supõe negociação entre dois “eus", cada um com seus gostos e seus projetos. Mais do que isso, a relação conjugal depende do delineamento de fronteiras, flexíveis mas eficazes, entre o território do eu, do nós-casal, do nós-família. Como refere Carolina, estar numa relação conjugal implica "Ser feliz sozinha, mas ser feliz a dois, obviamente".

Mais do que um simples paradoxo entre autonomia individual e fusão amorosa, em torno do qual argumentam alguns autores falando da crescente individualização nas sociedades contemporâneas, encontramos aqui uma estrutura tripartida de orientações - a autonomia pessoal, o investimento "intimista" na relação de casal, a dinâmica parental mais exigente de horários rígidos e cumprimento de tarefas familiares - que se procura conciliar. A disposição para "separar" as várias instâncias privilegiadas na vida privada (o eu, o casal, a família) parece, portanto, ser uma demanda vital no discurso reflexivo destas entrevistadas.

\section{Conclusões}

Da ênfase indutiva sobre os discursos femininos resultou a diversidade de categorias emergentes da realidade empírica, justificando sua discussão à luz da teorização sobre o amor em ciências sociais. É hoje indiscutível a colagem entre amor e conjugalidade, historicamente produzida pela domesticação da "paixão" erótica ou dos excessos ultraromânticos de veneração espiritual por uma amada inatingível, a favor de uma concepção do amor romântico como princípio vívido do casamento. Entretanto, atingida por crescentes transformações sociais no que respeita à individualização social, ao papel das mulheres e às relações de gênero, a visão romântica do amor tem incorporado novos elementos adequados ao aumento da autonomia feminina, à maior importância da realização pessoal, ao declínio da perenidade do casamento ou à crescente visão da sexualidade como área de eleição para a satisfação pessoal. Produzir-se-ia, assim, o "amor confluente" de que nos fala Giddens (1996). Até que ponto esse retrato é válido para qualificar a realidade evidenciada?

Uma primeira conclusão a assinalar aponta precisamente para a pluralidade de orientações amorosas na conjugalidade. Longe de haver um trajeto único ou uma semântica absolutamente dominante de expressão do sentimento, encontramos formas plurais de construção da afetividade na vida a dois. Se a constituição do casamento como relação de amor adquire características de hegemonia, demonstrando o impacto dos grandes processos de históricos de sentimentalização da vida familiar na estruturação da conjugalidade, é preciso também notar que as várias semânticas do amor (mais românticas, apaixonadas, amicais ou mesmo aproximadas ao ideal de "relação pura") se reatualizam nos discursos individuais de maneiras específicas. Existem, efetivamente, maneiras distintas de incorporação do amor romântico, do amor como amizade ou do amor como paixão, cada orientação reencontrando especificidades no formato das relações de gênero no casal, na concepção da identidade pessoal e do projeto de vida, nos valores e na visão global (mais institucionalista ou relacionalista) da conjugalidade e da família, bem como no tipo de fusão conjugal e de autonomia individual construídas dia a dia.

$\mathrm{Na}$ verdade, perfila-se uma diversidade de semânticas que, observada de um ponto de vista microssociológico, encerra maior complexidade do que a reconstrução macro-histórica da passagem do amor-paixão para o amor-romântico, ou do que o desenvolvimento mais recente do amor-confluente deixam adivinhar. $\mathrm{Na}$ expressão do "sentimento conjugal" aparecem misturadas diferentes conotações semânticas (do amor, da amizade, da paixão...), criando margens para variadas configurações. Umas, 
minoritárias, em que o amor é percebido como estático, outras, majoritárias, fundadas na dinâmica de companheirismo; umas em que o amor é complementaridade e aliança entre masculino e feminino, outras em que se procura romper com a tradicional diferenciação de gênero; umas em que se procura cooperação amical, outras em que se tenta manter viva alguma chama de apaixonamento; umas em que se tende a separar o amor das rotinas (como na "lógica de alternância"), outras em que se alimenta o amor de rotinas (como as formas de amor sustentadas primordialmente pela amizade).

No entanto, uma segunda conclusão importante deve observar o caráter indelével do romantismo como código amoroso do "apaixonamento" na conjugalidade. Trata-se, contudo, de um romantismo transformado, pois vários fatores indiciam mudanças na versão ultra-romântica do amor, que encontramos, por exemplo no caso de Matilde: um amor quase místico, subjetivamente estático e harmônico, intuitivo, pouco sexualizado em que se deseja uma "fusão de almas" e que apela à diferenciação entre masculino e feminino. No pólo oposto, o amor como paixão corpórea, não cotidiana, é também a orientação de uma minoria, associando-se normalmente a lógicas de grande separação do casal no dia-a-dia. Na verdade, a maioria das mulheres valoriza simultaneamente várias dimensões relacionais: o companheirismo, a cooperação e a busca de igualdade, ou pelo menos de entreajuda, aliamse aos lados amorosos da vida a dois. Estes são descritos como sensíveis ao tempo e exigentes de um trabalho de permanente edificação, justificando a noção de "amor-construção" (Torres, 2000). A própria sexualidade conjugal é normalmente assinalada como mais uma dimensão a alimentar ao longo da relação.

Apesar de os começos apaixonados serem majoritários no leque de situações investigadas, é também verdade que as definições do sentimento de paixão ou daquele que lhe sucede, transformando-o ou consolidando-o, seguem trajetórias bastante diversificadas. $\mathrm{Na}$ verdade, a comparação entre os dois discursos (um retrospectivo sobre o início e o outro sobre a atualidade) mostra talvez os aspectos mais interessantes da associação entre amor e conjugalidade.
Uma outra conclusão importante destaca, no sentimento inicial, o uso majoritário de uma semântica do amor apaixonado, marcada pela prioridade dos termos "paixão", "estar apaixonado", "atração" etc. O uso dessa terminologia reconstrói o período conjugal inicial como época de fusão forte, de querer estar com o outro numa altura de reestruturação pessoal, de construção de novas rotinas, de novas formas de organização da vida. Uma fase de fusão inicial freqüentemente descrita com recurso às categorias semânticas que o romantismo herdou do amor-paixão. Dizer-se apaixonado é também dizer-se em "estado de fusão" com o outro, associação perfeitamente encaixada no "deverser" normativo que alia casamento e amor. A fusão instaurada pelo sentimento amoroso dos começos conjugais é freqüentemente um elemento muitíssimo importante do processo de integração do casal, embora sofra as alterações promovidas, no tempo, pela necessidade de "diferenciação de si".

Mas também este retrato majoritário do apaixonamento inicial é fraturado por algumas exceções à regra. Uma delas destaca desde logo o amor-amizade e o companheirismo, a que não basta o imediatismo do amor, proposto pela idealização romântica, mas fundamentalmente a construção progressiva da amizade; o efeito repentino da flecha de Cupido idealizado pelo romantismo é afinal bastante diferente do sentimento progressivamente construído que é a amizade. Um outro modelo amoroso segue ainda o que consideramos ser a "lógica de alternância". Ao abrigo da idéia de relaçãoconstrução, numa incontornável mistura de amor e de rotinas, de amizade e de paixão, de espaço do eu e de espaço do nós, a justaposição de categorias semânticas já caracterizava, pelo menos na reconstrução retrospectiva do sentimento, o casal desde os primeiros tempos da sua formação.

Fundamentalmente, importa frisar que o amor é, na maioria dos casos, subjetivamente vivido como um processo dinâmico, sujeito às mutações trazidas pelos anos de vida em comum, ao ritmo da rotinização da conjugalidade. Assim se compreende que o sentimento atual, resultante de um trajeto a dois, seja descrito por uma terminologia mais variada e híbrida, enunciando a cumplicidade entre a dimensão afetiva e a dinâmica interna do casal ao longo 
do tempo. Assim se compreende a articulação entre paixão e fusão conjugal, entre o romantismo domesticado do amor-amizade e o aumento da "independência" feminina; entre um casal fortemente autônomo e orientações amorosas que abrigam em si formas de individualização. De fato, ambas as dimensões, afetos e cotidianos, perfilam um quadro de pluralidade que se apresenta, de um ponto de vista microssociológico, mais complexo do que aquele que as definições ideal-típicas de "casamento instituição", "fusão romântica" ou "associação individualista" propõem teoricamente. Os processos de individualização operantes nas sociedades atuais traduzem assim uma grande complexidade no âmbito do casal e das relações afetivas, desvelando lógicas pouco monolíticas que vão atravessando diferentes grupos sociais e mudando a geografia das oposições lineares entre tradicional e moderno.

\section{Notas}

1 Para Dumont, o individualismo supõe uma ideologia valorizadora do indivíduo nas sociedades modernas, por oposição ao holismo, a ideologia da totalidade social à qual se subordina o indivíduo nas sociedades hierárquicas.

2 O uso que fazemos do termo "semântica" referencia diretamente a análise que Luhmann (1991) faz do amor como código simbólico socialmente partilhado, observando nomeadamente as definições de amor expressas na literatura.

3 É preciso não esquecer, como sinalizam vários autores (Cancian, 1987), que o amor romântico foi sobretudo desenvolvido no feminino.

4 Nas entrevistas que realizamos entre meados de 2002 e início de 2003, privilegiamos uma inquirição biográfica, procurando registar o "lado subjetivo" do efeito gerado pelo tempo social: pedimos sistematicamente às 22 mulheres entrevistadas para nos relatarem as suas impressões comparativas sobre o tempo em que começaram a relação a dois e o momento presente, tendo encontrado em vários casos uma nítida percepção das transformações ocorridas na dinâmica do casal no espaço entre o início da conjugalidade e o momento de entrevista. A amostra foi construída segundo o método bola de neve que nos permitiu encontrar narrativas diversificadas. Apesar de uniforme em termos geracionais e de fase familiar, a amostra é socialmente diversificada, abrangendo mulheres de várias camadas sociais, populares e média ou média-alta. Todas as mulheres têm um trabalho remunerado mas diferentes qualificações profissionais e acadêmicas, oscilando desde o ensino primário até o doutoramento: dezessete mulheres vivem uma primeira conjugalidade, cinco tiveram percursos marcados por divórcio e recasamento, seis vivem em união consensual, sendo as restantes oficialmente casadas. Captar situações tão diversas foi, de fato, a nossa principal preocupação, de forma a garantir maior riqueza empírica à informação obtida.

\section{BIBLIOGRAFIA}

ABOIM, S. (2006), Conjugalidades em mudança: percursos e dinâmicas da vida a dois. Lisboa, Imprensa de Ciências Sociais.

ARIÈS, P. (1973 [1960]), L'enfant et la vie familiale sous l'Ancien Régime. Paris, Seuil.

BECK, U. \& BECK-GERNSHEIM, E. (1995), The normal chaos of love. Cambridge, Polity Press.

Publications.

BERGER, P. \& KELLNER, H. (1975 [1962]), "Marriage and the construction of the reality", in M. Anderson (org.), Sociology of the family: selected readings, Harmondworth, Penguin Education, pp. 302-323.

BOURDIEU, P. (1998), La domination masculine. Paris, Éditions du Seuil.

BOZON, M. \& HEILBORN, M. L. (1996), "Les caresses et les mots: initiations amoureuses à Rio de Janeiro et à Paris". Terrain, 27: 37-58.

BURGESS, E. W.; LOCKE, H. J. \& THOMES, M. (1960 [1945]), The family from institution to companionship. Nova York, American Book.

CANCIAN, F. M. (1987), Love in America: gender and self-development. Cambridge, Cambridge University Press.

CHAUMIER, S. (1999), La déliaison amoureuse: de la fusion romantique au désir d'indépendance. Paris, Armand Colin.

CHAVES, J. C. (2006), “Os amores e o ordenamento das práticas amorosas no Brasil da belle époque". Análise Social, 180: 827-846.

COSTA, S. (2005), "Amores fáceis: romantismo e consumo na modernidade tardia". Novos Estudos, 73: 111-124.

DAUSTER, T. (1984), “A invenção do amor: amor, 
sexo e família em camadas médias urbanas". Anais do IV Encontro Nacional de Estudos Populacionais, Associação Brasileira de Estudos Populacionais, pp. 521-539.

DOMINGUES, J. M. (2002), "Reflexividade, individualismo e modernidade". Revista Brasileira de Ciências Sociais, 49: 55-70.

DOUGLAS, J. D. \& ATWELL F. C. (1988), Love, intimacy, and sex. Londres, Sage.

DUMONT, L. (1985), O individualismo: uma perspectiva antropológica da ideologia moderna. Rio de Janeiro, Rocco.

DURHAM, E. (1997), “A pesquisa antropológica com populações urbanas: problemas e perspectivas", in R. Cardoso (org.), Aventura antropológica, Rio de Janeiro, Paz e Terra, pp. 17-37.

DURKHEIM, É. (1975 [1895]), "La famille conjugale", in , Textes III, Paris, Minuit, pp. 35-49.

EDGAR, D. \& GLEZER, H. (1994), "Famille et intimité: 'carrières' familiales et reconstruction de la vie privée". Revue Internationale des Sciences Sociales, 139: 141-165.

ELIAS, N. (1993 [1939]), A sociedade dos indivíduos. Lisboa, Dom Quixote.

FÉRES-CARNEIRO, T. (1998), "Casamento contemporâneo: o difícil convívio da individualidade com a conjugalidade”. Psicologia: Reflexão e Crítica, 2: 379-394.

FREUD, S. (1971 [1929]), Malaise dans le civilisation. Paris, PUF.

GIDDENS, A. (1996), As transformações da intimidade: sexualidade, amor e erotismo nas sociedades modernas. Oeiras, Celta.

GOODE, W. J. (1959), "The theoretical importance of love". American Sociological Review, 24: 38-47.

GUCHT, D. V. (1994), "La religion de l'amour et la culture conjugal”. Cabiers Internationaux de Sociologie, 97: 328-353.

KAUFMANN, J.-C. (1999), La femme seule et le prince charmant: enquête sur la vie en solo. Paris, Nathan.

KELLERHALS, J. et al. (1982), Mariages au quotidien: inégalités sociales, tensions culturelles et organisation familiale. Lausanne, Pierre-Marcel Favre.

LUHMANN, N. (1991), O amor como paixão: para a codificação da intimidade. Lisboa, Difel.

NEYRAND, G. (2002), "Idéalisation du conjugal et fragilisation du couple ou le paradoxe de l'individualisme relationnel'. Dialogue, 155: 80-88.

PARSONS, T. \& BALES, R. (1955), Family, socialization and interaction process. Nova York, The Free Press.

ROUSSEL, L. (1991), "Les types de familles", in F. de Singly (org.), La famille: l'état des savoirs. Paris, La Découverte, pp. 83-94.

SALEM, T. (1989), "O casal igualitario: princípios e impasses". Revista Crítica de Ciências Sociais, 3 (9): 24-37.

SENNETT, R. (1986 [1974]), The fall of public man. Londres, Faber.

SHORTER, E. (1995 [1975]), A formação da família moderna. Lisboa, Terramar.

SIMMEL, G. (1998 [1895]), "On the sociology of the family". Theory, Culture and Society, 15 (3-4): 283-293.

. (2004 [1992-1922]), Fragmento sobre o amor e outros textos. Lisboa, Relógio d'Água.

SINGLY, F. de. (1996), "L'amour et l'affection: un nouvel objet sociologique", in F. de Singly et al., La famille en questions: état de la recherche, Paris, Syros, pp. 97-101.

. (2000), Libres ensemble: l'individualisme dans la vie commune. Paris, Nathan.

SOLÉ, J. (1976), L'amour en Occident à l'époque moderne, Paris, Albin Michel.

STENDHAL. (1999 [1822]), Do Amor. São Paulo, Martins Fontes.

THÉRY, I. (2000), "Le couple occidental et son évolution sociale: du couple 'chaînon' au couple 'duo"”. Dialogue, 150: 3-11.

TORRES, A. (2000), Trajectórias, dinâmicas e formas de conjugalidade: assimetrias sociais e de género no casamento. Lisboa, tese de doutorado, ISCTE.

VAITSMAN, J. (1994), Flexiveis e plurais: identidade, casamento e família em circunstânciaspós-modernas. Rio de Janeiro, Rocco. . (1997), "Pluralidade de mundos entre mulheres de baixa renda". Estudos Feministas, 5 (2): 303-319.

VELHO, G. (2002 [1986]), Subjetividade e sociedade: uma experiência de geração. Rio de Janeiro, Zahar.

WAGNER, P. (2001), Theorizing modernity: inescapability \& attainability in social theory. Londres, Sage.

WIDMER, E.; KELLERHALS, J. \& LEVY, R. (2003), Les couples contemporains: cohésion, régulation et conflits. Zürich, Séismo. 


\section{DA PLURALIDADE DOS AFETOS: TRAJETÓRIAS E ORIENTAÇÕES AMOROSAS NAS CONJUGALIDADES CONTEMPORÂNEAS}

\section{Sofia Aboim}

Palavras-chave: Orientações amorosas; Trajetos; Conjugalidade; Individualização; Modernidade.

Num contexto em que a construção do casamento como relação de amor adquire hegemonia nas sociedades contemporâneas, trazemos à arena empírica o debate sobre a sentimentalização da conjugalidade e a crescente complexidade promovida pelos processos de individualização. Analisando discursos de mulheres portuguesas vivendo em conjugalidade, descrevemos a pluralidade das orientações amorosas nas conjugalidades atuais. Observamos o entrecruzamento entre romantismo e aliança, companheirismo e paixão erótica, autonomia individual e fusão amorosa. Revela-se, assim, um cenário heterogêneo, onde o amor adquire múltiplos significados, percorre diversos caminhos e se articula a formas de construir o cotidiano na vida a dois.

\section{OF PLURALITY AND \\ AFFECTION: TRAJECTORIES OF LOVE AND INTIMACY IN CONTEMPORARY PARTNERSHIPS}

\section{Sofia Aboim}

Key-words: Affection; Trajectories; Conjugality; Individualization; Modernity.

In face of the massive historical transformations occurring in family live, which have led conjugal relationships to be constructed upon affection, this article aims to debate the relationship between historical sentimentalization and the growing complexity generated by individualization processes. The analysis of discourses of Portuguese married or cohabiting women enabled us to describe a variety of trajectories and orientations towards love and intimacy, thus showing the plurality of affections in contemporary conjugalities. On the other, companionship seemed to associate with erotic passion. At the same time, highly individualized women always reveal some tension between autonomy and intimate fusion with the partner. Showing the linkages between different conjugal trajectories and the building up of these semantics of affection, we disclose a heterogeneous scenario, where love acquires multiple meanings, follows different pathways and is interwoven with the construction of the couples' daily life.
DE LA PLURALITÉ DES

AFFECTS: TRAJECTOIRES ET ORIENTATIONS AMOUREUSES DANS LES CONJUGALITÉS CONTEMPORAINES

\section{Sofia Aboim}

Mots-clés: Orientations amoureuses; Trajets; Conjugalité; Individualisation; Modernité.

Dans un contexte où la construction de la conjugalité comme relation d'amour est devenu presque hégémonique dans les sociétés contemporaines, on apporte à l'arène empirique le débat sur la sentimentalité moderne de la conjugalité et la croissante complexité engendré par les processus d'individualisation. En analysant les discours des femmes portugaises vivant en couple, on décrit la pluralité des orientations amoureuses dans les conjugalités actuelles. On observe le croisement entre romantisme et alliance, compagnonnage et passion érotique, autonomie individuelle et fusion amoureuse. Ainsi, dans cet article on révèle une réalité hétérogène, d'autant que l'amour recouvre des signifiés multiples et parcourre chemins diversifiés en s'articulant a des formes spécifiques de construire a deux la vie quotidienne. 